\title{
versants
}

\section{Les vertus universelles}

Henri ROORDA

Écrivain

\begin{abstract}
Dans cette chronique de 1919, reprise en 202I dans le recueil Intelligence à louer (Genève, La Baconnière), Roorda passe en revue les qualités qui pourraient conduire à une amélioration de la vie humaine, avant de déclarer forfait.

Keywords : Henri Roorda, rêve, perfectibilité, utopie.
\end{abstract}

Je continue à perdre mes illusions une à une ; et je prévois que ça va mal finir. Avant le I5 mai, il ne m'était jamais arrivé de mettre en doute la valeur absolue des grandes vertus humaines. Je ne les pratiquais pas toutes, car cela aurait humilié les êtres faibles au milieu desquels je vis ; mais, dans le secret de mon cœur, je les aimais sans restrictions.

Or, dans la nuit du I4 au I5 mai, j'ai fait un rêve. Assis sur un haut tabouret en forme de trône, je disposais, pour une heure, du pouvoir inouï d'améliorer d'un seul coup tous les représentants du genre humain. Plus exactement, je pouvais, par un simple décret, donner pour toujours, à tous mes contemporains, une grande qualité - mais une seule, et la même pour tous. Et j'avais soixante minutes pour la choisir.

Accroupi aux pieds de mon tabouret, un personnage silencieux et mystérieux attendait ma décision. Et, en face de moi, il y avait une grande horloge que je regardais de temps en temps ; car je ne voulais pas, par un retard stupide, priver les hommes du cadeau magnifique que j'étais en mesure de leur faire.

— Vais-je les rendre intelligents, me disais-je ; ou courageux ? ou bons? ou beaux? ou bien, donnerais-je à chacun d'eux une volonté de fer?

Je n'avais que l'embarras du choix. Ce qui me rassurait, c'était que mon présent, quel qu'il fût, aurait un prix inestimable.

J'avais d'ailleurs le temps de réfléchir. Si tous les hommes étaient intelligents, les peuples ne seraient plus ces troupeaux dociles dont la crédulité me désespère. Et les beaux jours des roublards de la politique seraient finis. C'est certain. Mais..., mais... (je devins tout à coup inquiet), l'affranchissement intellectuel de tous les individus ne produirait-il pas dans la société une révolution terrible? Notre civilisation moderne n'est possible que dans un monde où des êtres innombrables consentent à vivre comme des bêtes de somme. Il y a aujourd'hui des travaux "bêtes" et pénibles qui doivent absolument être faits. Des individus intelligents voudraient-ils s'en charger? 
Vous dites qu'ils trouveraient la solution du problème. Est-ce bien sûr ? Et puis la trouveraient-ils assez rapidement?

Hélas ! je le devine : l'intelligence ne suffirait pas ; il faudrait, en plus, de l'abnégation. Mais le temps passe. N'hésitons pas trop. Je vais donner à chacun de mes contemporains un immense courage ; et désormais, l'être humain saura se défendre contre tous ceux qui l'exploitent ou qui l'oppriment. Ce sera la fin de la vieille injustice. Aube des temps nouveaux, je te salue... ! Bon! Voici que j'hésite encore. Aujourd'hui, les hommes que la peur des coups rend conciliants et pacifiques se comptent par millions. La paix sera-t-elle possible lorsque les individus, séparés par leurs croyances, seront toujours prêts à la lutte?

Mais voici la solution du problème. La bonté est la vertu souveraine. Si les humains étaient bons les uns pour les autres, leur misère prendrait fin. Ceux qui souffrent seraient toujours sûrs d'être aidés, et consolés... Hum ! Cette absolue sécurité n'offrirait-elle pas de graves inconvénients? Je connais quelqu'un qui sera bien imprévoyant et qui fera bien des sottises lorsqu'il pourra compter sur la bonté des autres.

Que vois-je ? Il me reste encore cinq minutes pour réfléchir. La loyauté est une vertu de premier ordre. Mais les affaires sont les affaires. Que deviendrait le commerce, que deviendrait la vie sociale, si, à partir de demain matin, chaque citoyen cessait définitivement de mentir? Je frémis rien qu'en y pensant.

Je suis décidé : la vie aura incontestablement plus de charme quand tous les êtres seront beaux... Eh ! bien, non ! Je renonce. Le baron Chose, qui a une âme d'artiste, tomberait amoureux de sa blanchisseuse, de sa cuisinière et de sa concierge si ces dames n'avaient plus cette laideur de tout repos qui nous a si souvent frappés. J'en suis sûr : le brusque embellissement de la race humaine altérerait gravement la pureté de nos mœurs. Et, nousmêmes, nous serions si différents, que nos amis ne pourraient pas nous reconnaître...

D’ailleurs, l'heure est écoulée. L'inconnu qui était accroupi au pied de mon trône a subitement disparu. Mon rêve a pris fin et je me retrouve dans mon lit. Ouf! L'humanité l'a échappé belle !

Tribune de Lausanne, $\mathrm{I}^{\mathrm{er}}$ juin $\mathrm{I} 9 \mathrm{I} 9$ 